\title{
The Secret of Brahms Cellos Sonata No. 1 Op. 38 and Shostakovich Cello Sonata Op. 40
}

\author{
Asep Hidayat Wirayudha \\ Graduate School of Indonesia Institute of the Arts Yogyakarta
}

\begin{abstract}
ABTRACT
This study aims to find a technique solution behind the Far interval and Octave interval in Brahms Cello sonata no.1 opus 38 and Shostakovich cello sonata op. 40 through literature and Discography approach. The fingering problems may poses special difficulties to any cellists. According to the author's assessment, there are two problems that warrant special attentions of the cellist. Both intervals may cause serious problems on the performance of short fingers cellists. The size of the fingerboard on the cello as compared to other string instruments are longer, resulting in harder difficulties regarding obtaining tone (Stowell, 1999). From the results of the Far Interval and Octave Interval and active involvement of the researchers, the results show that, what is shown that every cellist are anatomically different. The fingers of the cellists are naturally very flexible. It cannot be converted to another cellists. So flexibly that it is possible to overcome the problem in a simple and convenient. Keywords: Brahms Sonata cello No.1 opus 38, Shostakovich, octave, interval
\end{abstract}

\section{INTRODUCTION}

The principles of neck-positions fingerings on cello have been evolved since the cellist of eighteenth-century extended their range beyond the first position. The principles have greatly improved the skill of cellists to performs musical composition. However, by its nature, fingering is a personal matter. What is regard as suitable principles or rules to one hand will not always suit another. Therefore, one cannot lay down any strict rules of fingerings although there are certain general principles that can be followed. Among many factors determines the suitability of any principles of cello fingering, the size of cellists fingers is one factor that seemingly out of notice. The available cello fingering methods generally suitable for cellist having relatively long fingers. Those having relatively short fingers may find many difficulties to apply the principles. The aforementioned condition, which may cause serious problems on the performance of short-fingers cellists, warrants new methods or approaches to improve their skills. It is in this contexts the author process modifications of the available octave and far interval etudes in order to improve the performance of cellist. The Brahms cello sonata cello No. 1 op. 38 and the Shostakovich cello sonata op. 40 are used as cases of point.

Within the context of Brahms Sonata cello No. 1 opus 38, and the Shostakovich cello sonata opus 40, the author divides the problem into two types. They are : (1) octave interval and (2) far interval problem. In order to make the problems clear, it 
is imperative to define first the octave and far intervals. Octave interval are intervals where cellist have to play two musical notes from the necessity to place the fingers in two far-separated positions. Such a necessity may cause the short-finger cellists pain and discomfort. Some cellists moreover may not reach the proper position at all.

Far interval are intervals where cellists have to move from one note to another that at least one octave higher or lower in a short time. Far intervals, especially those required cellists to change position, are classic problem for virtually any cellists. The following passages describe the octave interval in the Brahms cello sonata No. 1 opus 38, and Shostakovich cello sonata opus 40 which according to the author's assessments, may become serious problems to any short- fingers cellist. There for, those intervals were selected from the point of view of the relatively short-finger cellists. It followed then by the expositions of far intervals, from the same sonatas that may become problem for many cellist.

\section{OCTAVE INTERVAL PROBLEMS}

There are seven octave intervals of Brahms cellos sonata No.1 opus 38 that present special difficulties for the short-fingers cellists. The first difficulty is located at the first movement, measure (figure 2-1)

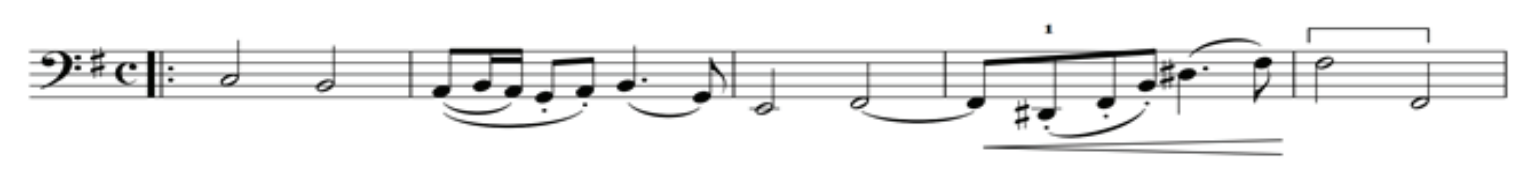

Figure 2-1. Octave interval at the first movement, measure 5 of the Brahms cello sonata No. 1, opus 38 .

The difficulty to perform this interval come from the fact that it requires the first and the fourth fingering to spread on two relatively far-separated notes, especially on the lower note. The second difficulty is located at the first movement measure 130 (figure 2-2)

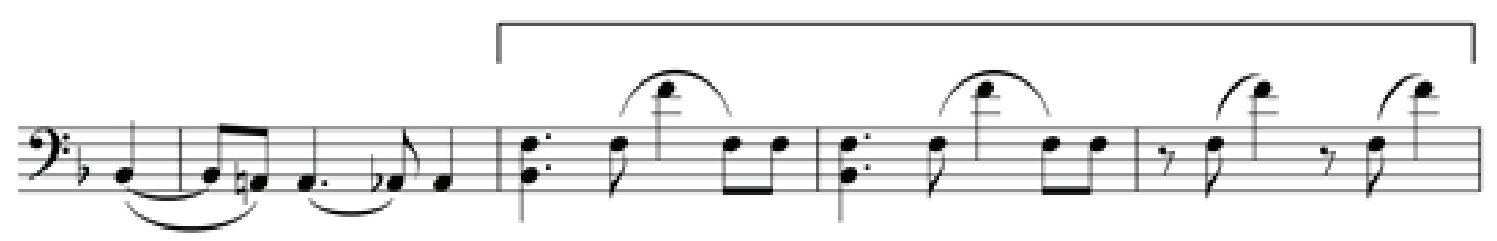

Figure 2-2. Octave interval at the first movement, measure 130 of the Brahms cello sonata No. 1 , opus 38 .

This interval became difficult to be performed since it compels two far-separated notesthe $B b$ and $F$ to be played at the same time in the context of fortissimo. The similar difficulties are found at the third movement, measure 13,35 and 45 (see figure 2-3 to 2-5). 


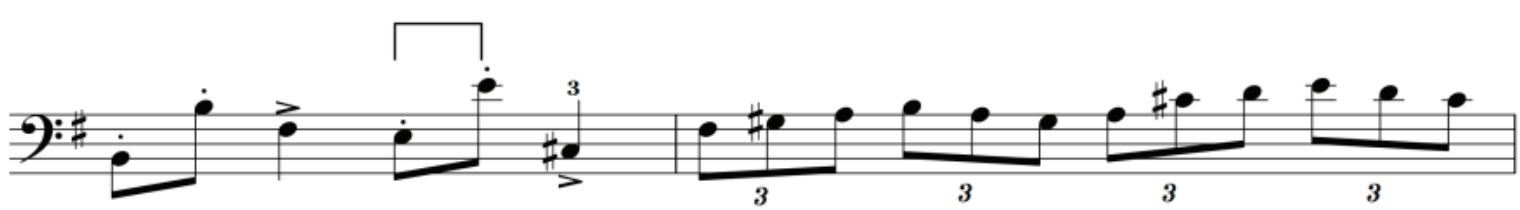

Figure 2-3. Octave interval at the third movement, measure 13 of the Brahms cello sonata No. 1, opus 38 .

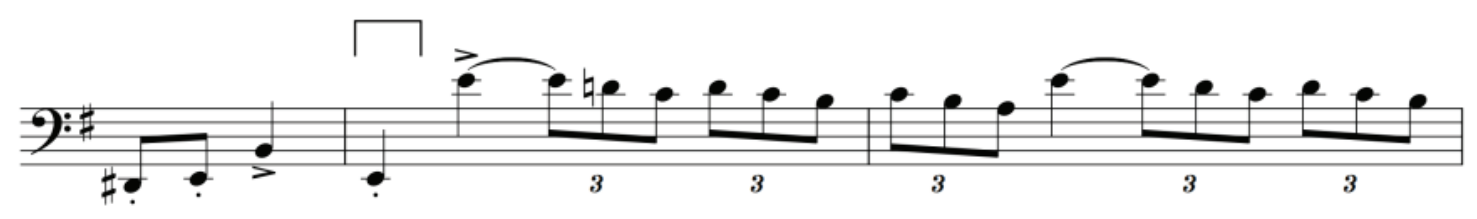

Figure 2-4. Octave interval at the third movement, measure 35 of the Brahms cello sonata No. 1, opus 38 .

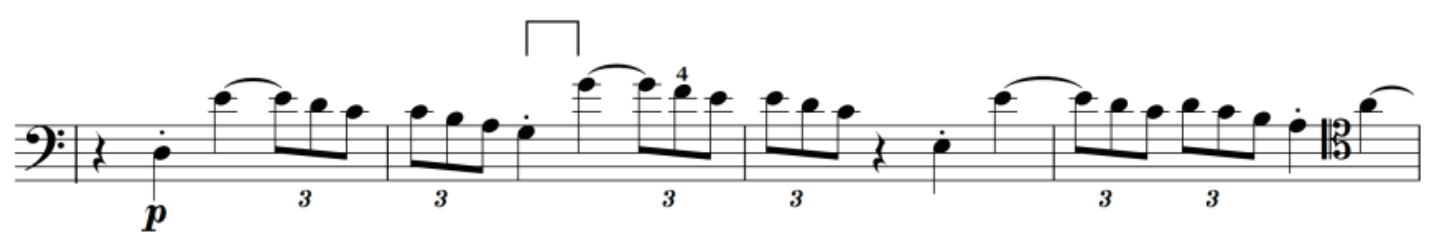

Figure 2-5. Octave interval at the third movement, measure 45 of the Brahms cello sonata No. 1, opus 38 .

The sixth and relatively difficult octave interval situated at the second movement, measure 49 (figure 2-6)

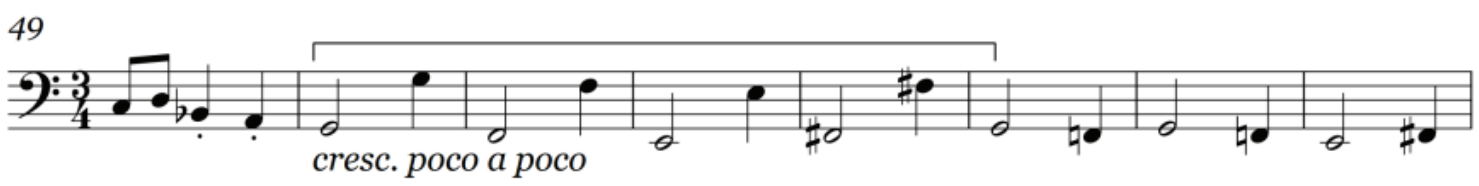

Figure 2-6. Octave interval at the second movement, measure 49 of the Brahms cello sonata No. 1, opus 38 .

The problem on this octave interval occurs from the difficulty to use the first and the fourth finger in order to exploit optimally lower notes in the contact of fortissimo. The seventh point of difficulty is found at the third movement, measure 31 (figure 2-7)

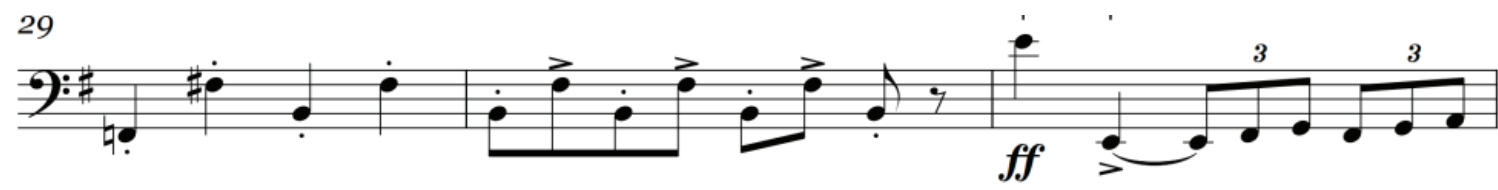

Figure 2-7. Octave interval at the second movement, measure 31 of the Brahms cello sonata No. 1, opus 38 . 
The difficulty to play the aforementioned interval come from the necessity to play the near- scroll interval atfast tempo and the dynamics of fortissimo.In the Shostakovich cello sonata Opus 40, the author finds four octave intervals that may become problem to the short-fingers cellist. The first interval is located at the first movement, measure 71 (figure 2-8).

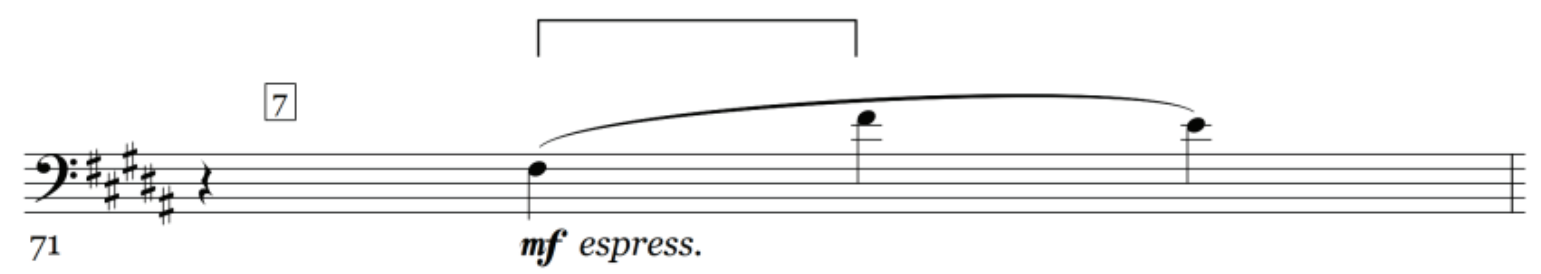

Figure 2-8. Octave interval at the first movement, measure 71 of the Shostakovich cello sonata opus 40.

The difficulty to perform this interval occurs from the necessity to move the lower $F \neq$ to upper $F \neq$ at short time under the legatissimoexpressivo. Other point of difficulty is located at the first movement, measure 149 (figure 2-9). This interval in figure 2-9 become difficult to be performed since it requires twofar-separated notes-the lower $E b$ and upper $E b$ to be played in the context of fortissimo. The similar difficulty are found at the first movement, measure 130, in the Brahms cello sonata No.1, Opus 38, (see figure 2-2)

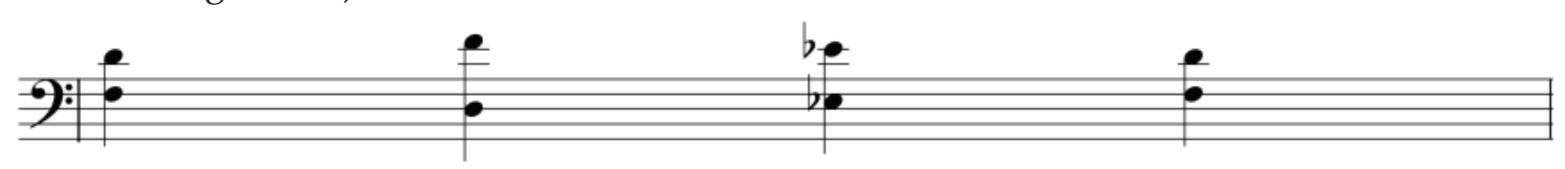

Figure 2-9. Octave interval at the first movement, measure 149 of the Shostakovich cello sonata opus 40.

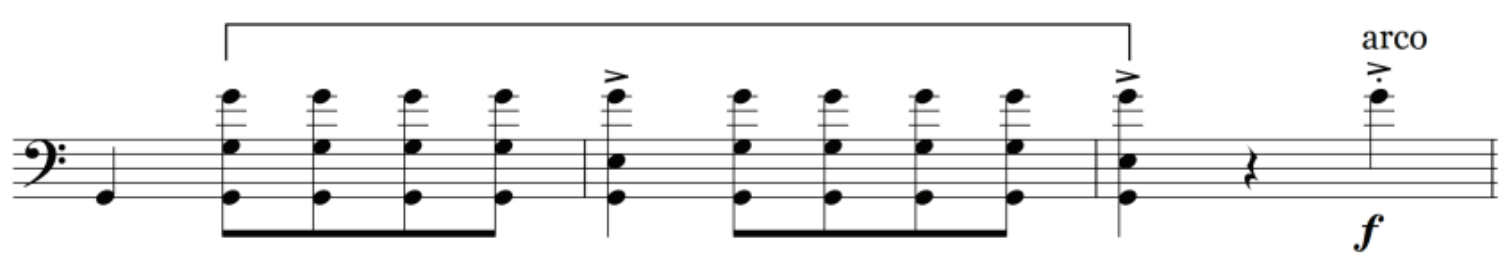

Figure 2-10. Octave interval at the second movement, measure 61-63 of the Sostakovich cello sonata Opus 40.

The fourth point is situated at the third movement,measure 74 (see figure2-11) 


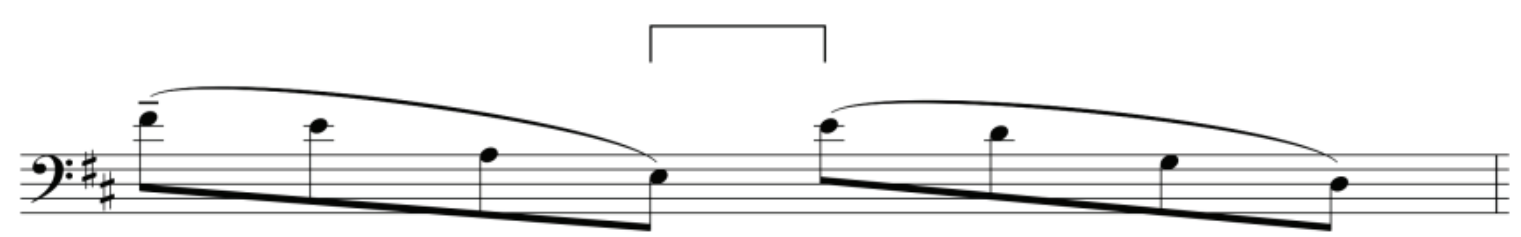

Figure 2-11. Octave interval at the third movement, measure 74 of the Shostakovich cello sonata Opus 40.

The interval above may become a problem since it necessitates the cellists to play the interval in the dynamics of piano phrase. Such a necessity may cause the phrase unclear.

\section{THE FAR INTERVAL PROBLEM}

There are four far intervals of the Brahms cello sonata No. 1 Opus 38. They are located at the first movement, measure 26-29 and 110-112 and at the third movement, measure 115 and 166-169. The difficulty to play the first point (figure 2-12) occurs from the fact that, firstly (at measure 26), it compels the cellist to move from the first to the fifth position and, secondly (at measure 28), from the fourth to the sixth position.

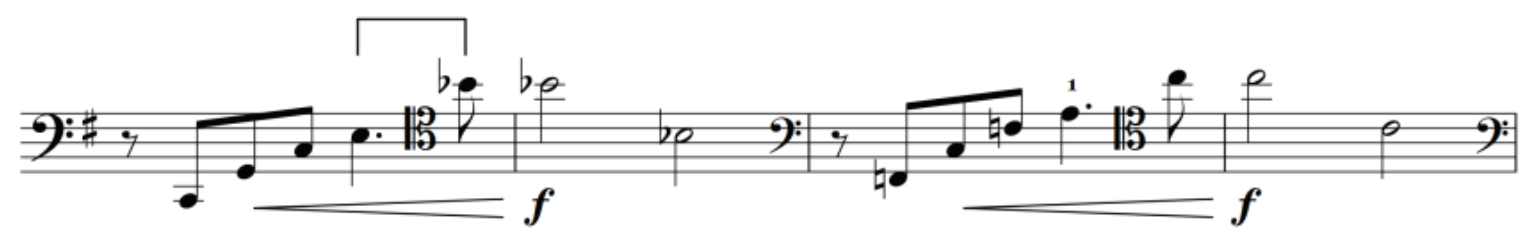

Figure 2-12. Far interval at the first movement, measure 26-29 of the Brahms cello sonata No. 1, opus 38 .

The second point of difficulty (figure 2-13) necessitates the cellist to move, in a short time, from the $D b$ in the fourth beat of the measure 110 to the same note situated one octave higher. Moreover, such a movement is followed by the shifting, also in a short time, from the lower $F$ of measure 112 to the upper $F$ that is two octave higher.

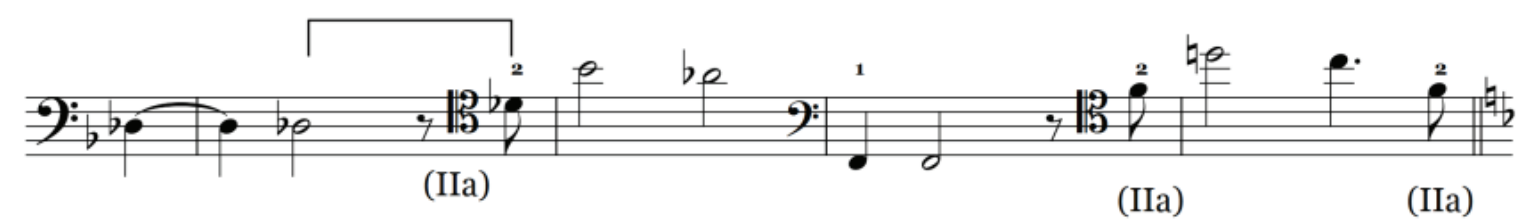

Figure 2-13. Far interval at the first movement, measure 110-112 of the Brahms cello sonata No. 1, opus 38 .

The far interval at the third movement, measure 115 (figure 2-14) presents the optimality problem of the sound quality since it necessitates the cellists making a relatively far shifts. 


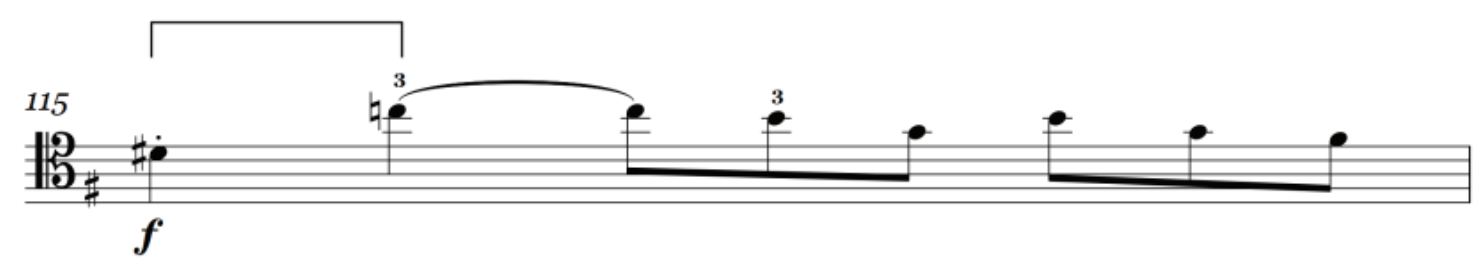

Figure 2-14. Far interval at the third movement, measure 115 of the Brahms cello sonata No. 1, opus 38 .

The last far intervals that difficult to be performed, located at the third movement, measure 166-169 (figure 2-15). They compel the cellist to move from the note $B$ to the note $C \neq$ that is three- octave higher. This is difficult to be played (it is the farthest interval in the Brahms cellos sonata No. 1 opus 38). Moreover, this may become a problem since it is located at the third movement. At that moment, the fingers may have already exhausted from the previous movement. According to the author's assessments, there are two far interval problems in the Shostakovich cello sonata Opus 40. They are located at the first movement, measure 33 and 42.

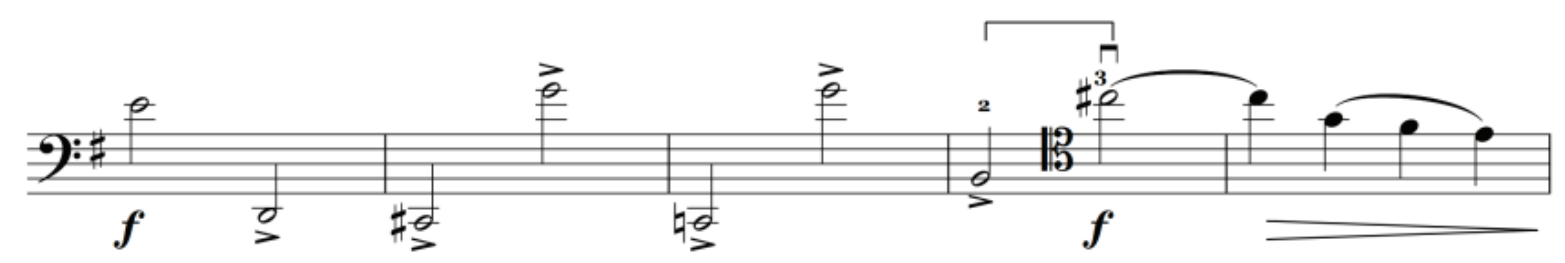

Figure 2-15. Far interval at the third movement, measure 166-169 of the Brahms cello sonata No. 1, Opus 38.

The first difficulty (figure 2-16) present a classic intonation problem. It compels the cellists to move from $\mathrm{F}$ in the fourth position to $\mathrm{D}$ in the fifth position.

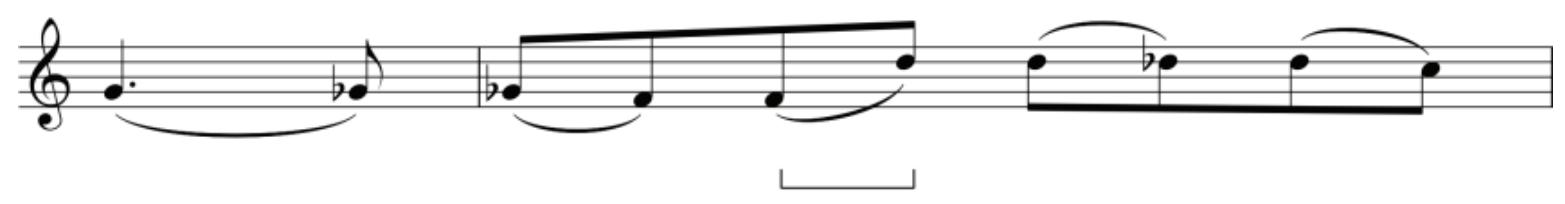

Figure 2-16. Far interval at the first movement, measure 33 of the Shostakovich cello sonata Opus 40.

The second point of difficulty (figure 2-17) present a specific difficulty to short-finger cellists since they would find a constrain in order to spread their fingers properly on the note $\mathrm{C}$ and $\mathrm{F}$ in the seventh position.

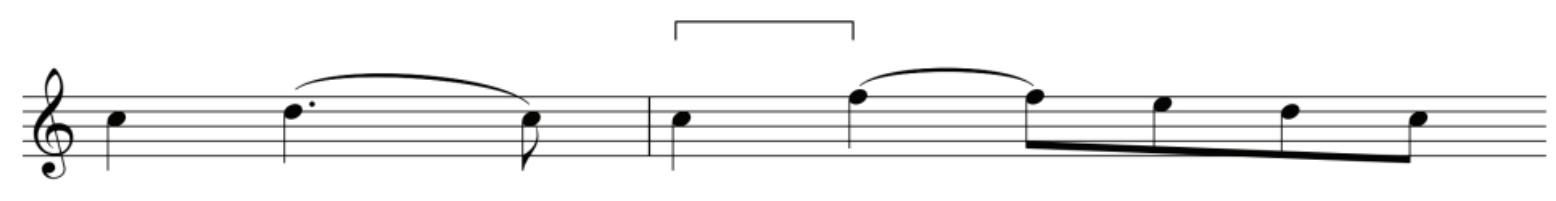

Figure 2-17. Far interval at the first movement, measure 42 of the Shostakovich cello sonata Opus 40. 


\section{SOLUTION TO THE OCTAVE INTERVAL PROBLEM}

Fingers, by theirs nature, are flexible since they are built mainly by soft tissues and muscles. The flexibility of fingers is one main factor responsibility their spreadability. Considering the cello playing, the spreadability of cellists fingers is very important since it has a direct correlation to their ability to play the octave interval. The shortfingers cellists would find difficulties to play the octave intervals at the first, second, third, and fourth position. Nevertheless, short-fingers are not dead-end for cellist. The spreadability of finger, up to some extend, might be increase through practice and exercises. It is with this spirit the author proposes some stratagems, which may be used to increase the spreadability of a cellists fingers in this section, using the octave interval problems as case of pint. The discussion on the types and styles of problem show that even though the octave intervals in Brahms cellos sonata No. 1 opus 38, and Shostakovich cello sonata opus 40 are different in details, but fundamentally they are the same: the problems came from the difficulty of the first and the fourth fingers to reach the proper note when the size and length of the fingers are limited. The difficulty may be solved through the exercises depicted in figure 3-1. The authors proposes six of exercises that may be used to increase the spreadability of short-fingers cellist. The exercises are directed to the $G$ string. All of the excercises, however may be applied and modified to other strings, fingers, and rhythms according to the personal need.

\section{SOLUTION TO THE FAR INTERVAL PROBLEMS}

Solution to the Problem at the First Movement, Measure 26-29 of the Brahms cellos sonata No. 1 opus 38

The fingers shifting always become problems. In the case of the movement 1 , measure 26-29 of the Brahms cellos sonata No. 1 opus 38 (figure 2-12), the requirement of fingers to shift from $E$ (first position) to $B_{\mathbf{b}}$ (fifth position) may result the discordant tone of the $B b$. To solve this problem, the author proposes the following exercise (figure 3-2). It consist of the playing of the E and G (open string) in slow tempo, to make sure that the intonation are concordant, following by the sifting from the $E$ to $A$ (open string) in slow tempo and glissando using the second finger. Such a position would make the $\mathrm{Bb}$ could be reached easily using the third finger. The repeatation of this exercise using the $E-A$ $B \mathrm{~b}, B \mathrm{~b}-A-E$, and their variations would give a better results. 

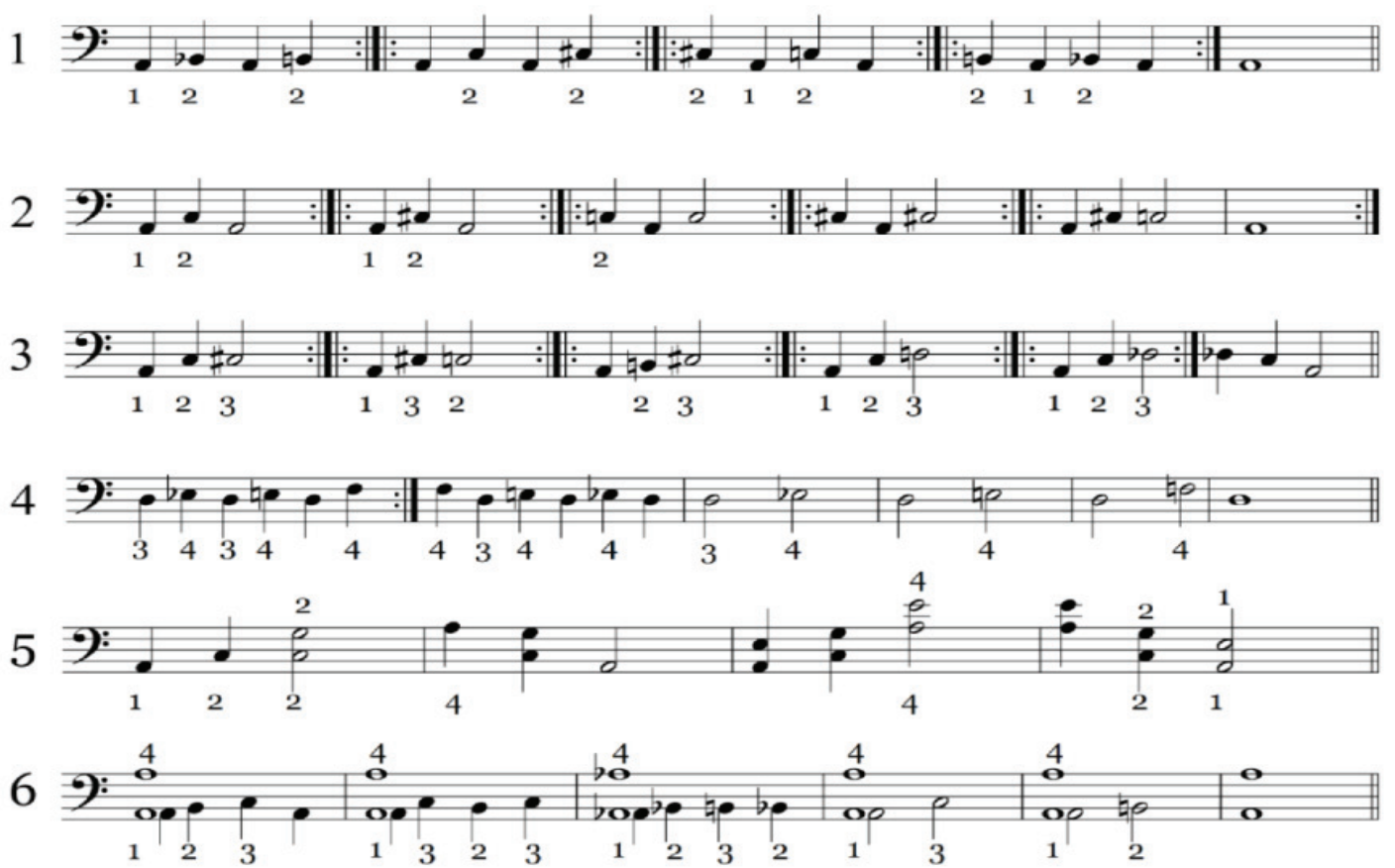

Figure 3-1. Six variations of exercises to increase the spreadability of short-fingers celists.

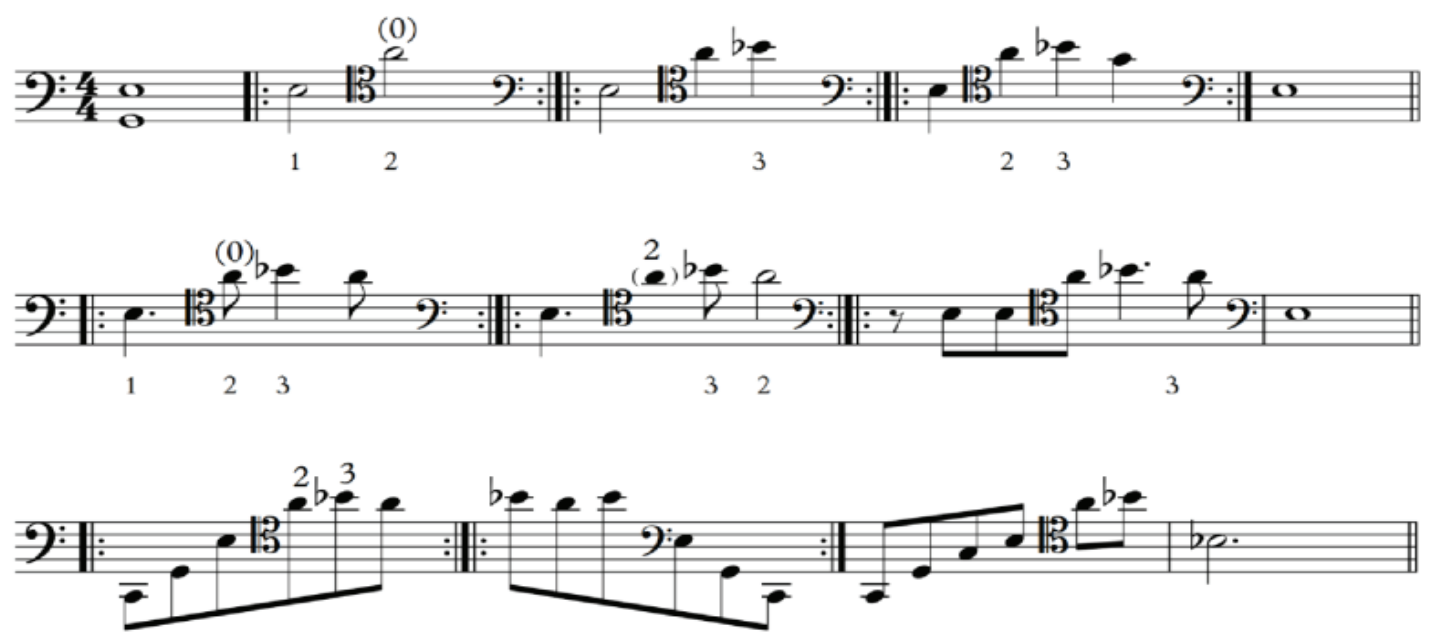

Figure 3-2. Three-steps exercise to practice the shifting from the $\mathrm{E}$ to $\mathrm{B} b$.

Solution to the Problem at the First Movement, Measure 110-112 of the Brahms cello sonata No. 1 Opus. 38

To solve the problem at the case of the movement 1 , measure 110 of the Brahms cellos sonata No.1 Opus 38, (see figure 2-13), the author proposes the following exercise (figure 3-3). Firstly, play of the lower $D$, and approaching the fifth position, its role is changed by the second fingers. The pressing of the $D$ string (flageolet) by the third finger should be used as an intonation controller. 


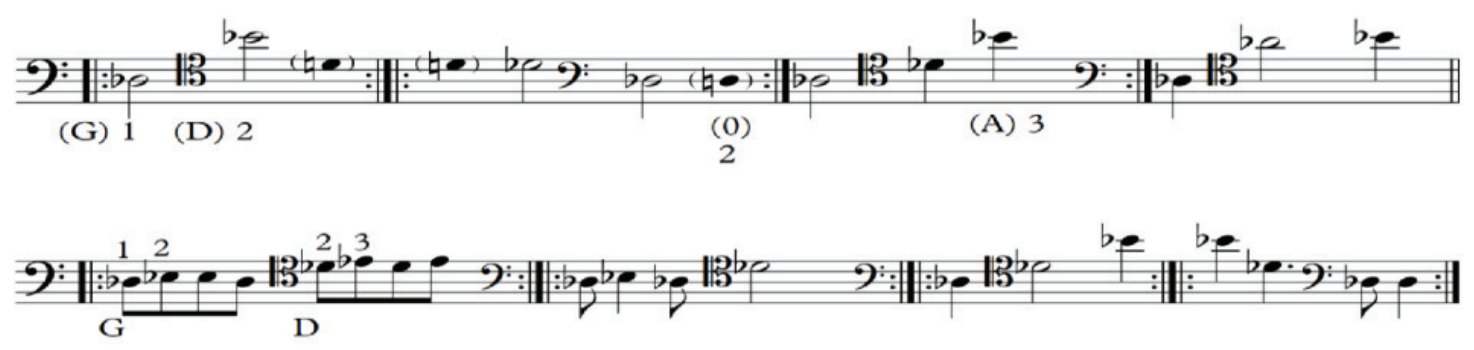

Figure 3-3. Two-steps exercise to practice the shifting from the lower $\mathrm{D} b$ to the upper $\mathrm{D} b$.

The solution to the problem at the movement 1 , measure 112 of the Brahms cellos sonata No.1

Opus 38, (figure 2-13) is basically the same as those for the measure 110. There are two alternatives to shift from the lower $F$ to the upper $F$ notes. The first alternative is pressing the lower $\mathrm{F}$ note that is located at $A$ string using the second finger (four position). Consequently, the $D$ note that should be play at the first beat of the measure 111 is located relatively far from the $F$ note and may not be reached properly. The possibility to use this alternative successfully would be increase through the following exercise (figure 3-4). Firstly, play the $F$ note using the second finger in the slow tempo. Secondly, shift to the fifth position. By the end of this motion, the $D$ major scale is established which, in turn, making the $D$ note reachable.

The second alternative (figure 3-5) is started by pressing the lower $F$ note that is located at the $D$ string using the first finger (fifth position). The pressing of the $D$ string (flageolet) by the thumb should be used as an intonation controller. In such a configuration, the upper $F$ note may be then reached by the second finger at the $A$ string (fifth position).

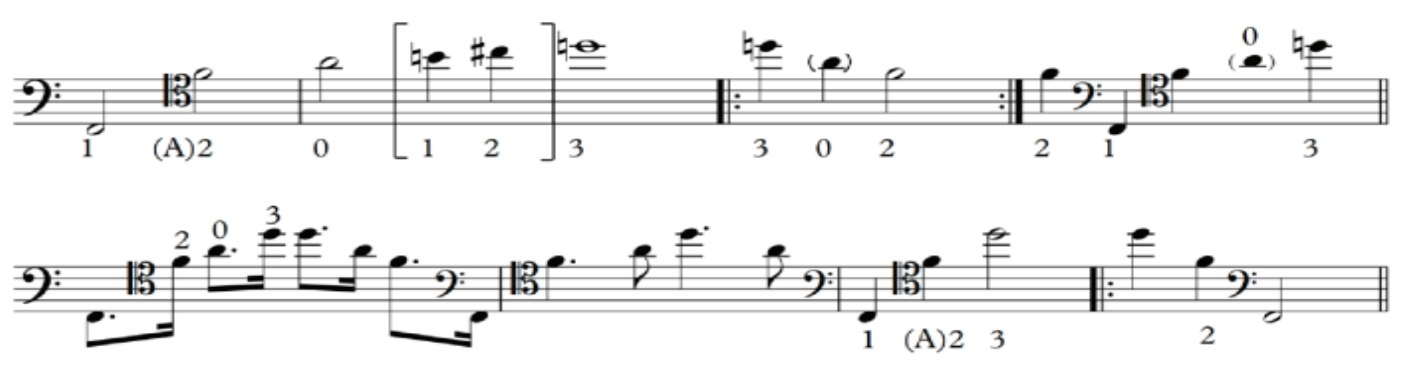

Figure 3-4. The first alternative of the two-steps exercise to practice the shifting from the lower $F$ to the upper $F$.

From the aforementioned explanation, it is clear two alternative are similar the main difference in the string used to define the lower $F$ notes. 

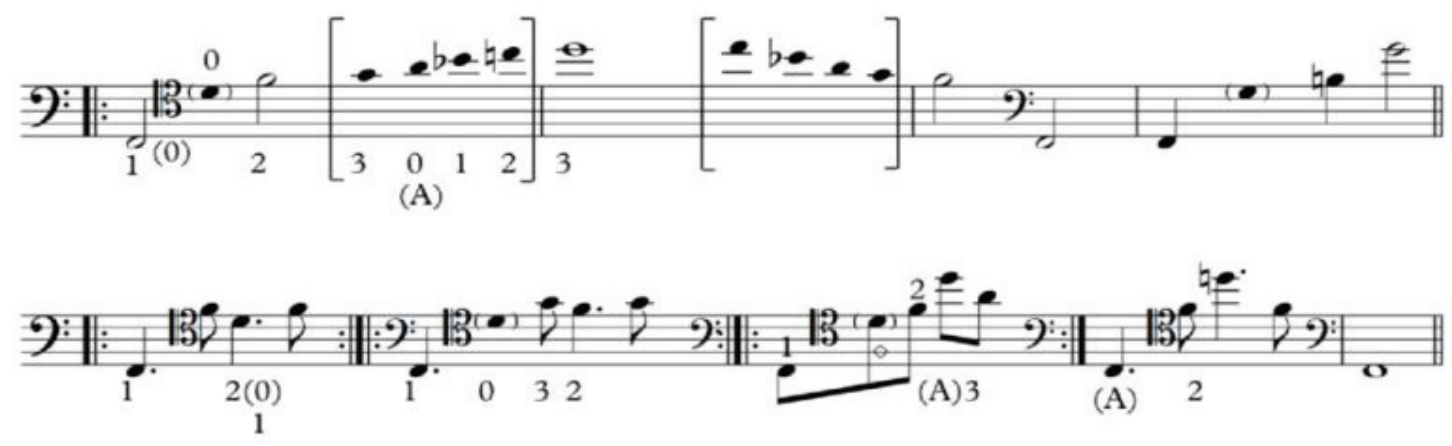

Figure 3-5. The second alternative of the two-steps exercise to practice the shifting from the lower $F$ to the upper $F$.

Solution to the Problem at the Third Movement, Measure 115 of the Brahms sonata No.1 opus 38.

To solve the problem at the third movement, measure 115 of the Brahms cellos sonata No. 1 opus 38, (see figure 2-14), the author proposes the following exercise (figure 3-6). Firstly, press the $D \neq$ note using the third finger. Secondly, shift to find and reachable easily using the third finger. Pressing the $A$ string (flageolet), before shifting from $D \neq$ to $C$, may be done control the intonation.
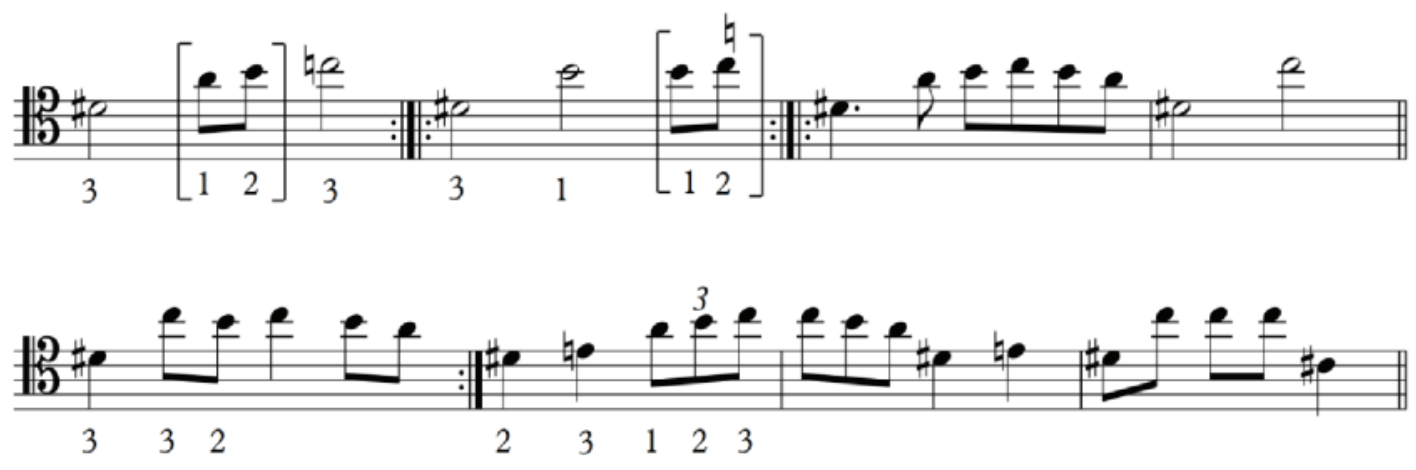

Figure 3-6. Two-steps exercise to practice the shifting from $D \#$ to $C$.

Solution to the Problem at the Third Movement measure 169 of the Brahms Cello sonata No. 1 opus 38.

To solve the problem at the third movement, measure 169 of the Brahms cello sonata No. 1 opus 38, (see figure (2-15, the author propose the following exercise (figure 3-7). In essence, the exercise is similar to those for the third movement, measure 115 of the Brahms cello sonata No.1 opus 38, explained above.

Firstly, press the $B$ note using the third finger. Secondly, shift to find and press the $A$ note using the thumb in glissando. By controlling the flageolet, to make the fifth position, then the $C \neq$ would be reached easily. 

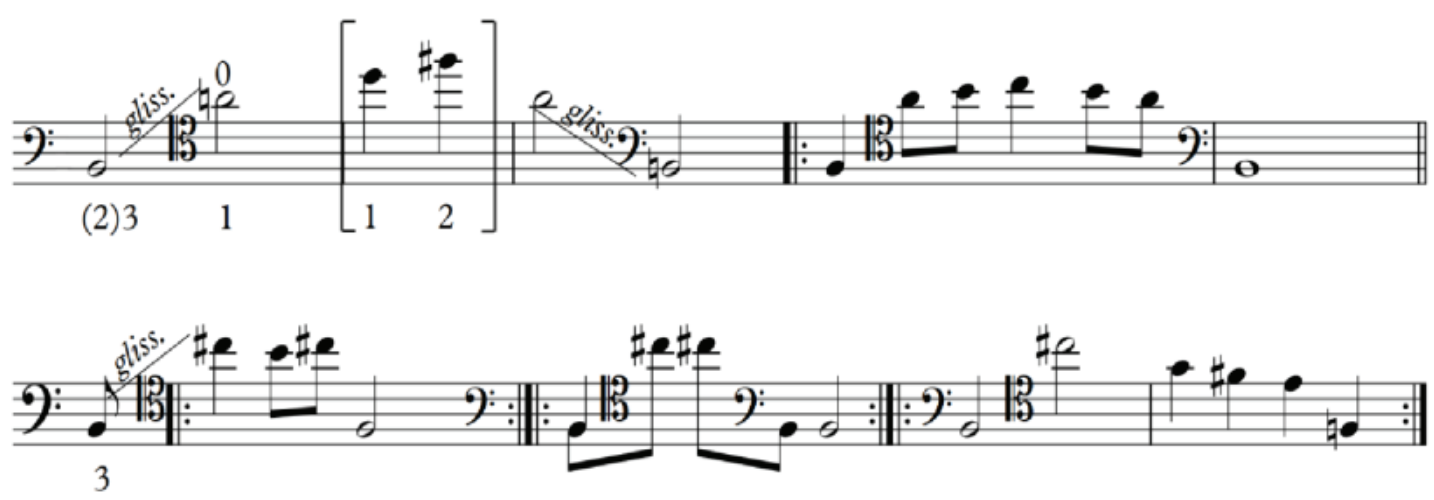

Figure 3-7. Two-steps exercise to practice the shifting from the $B$ to $C \#$.

Solution to Problem at the First Movement, Measure 33 of the Shostakkovich Cellos sonata. Opus 40

One alternative solution for the problem of the first movement, measure 33 of the Shostakovich cello sonata opus 40 (see figure 2-16) is depicted in figure 3-8.

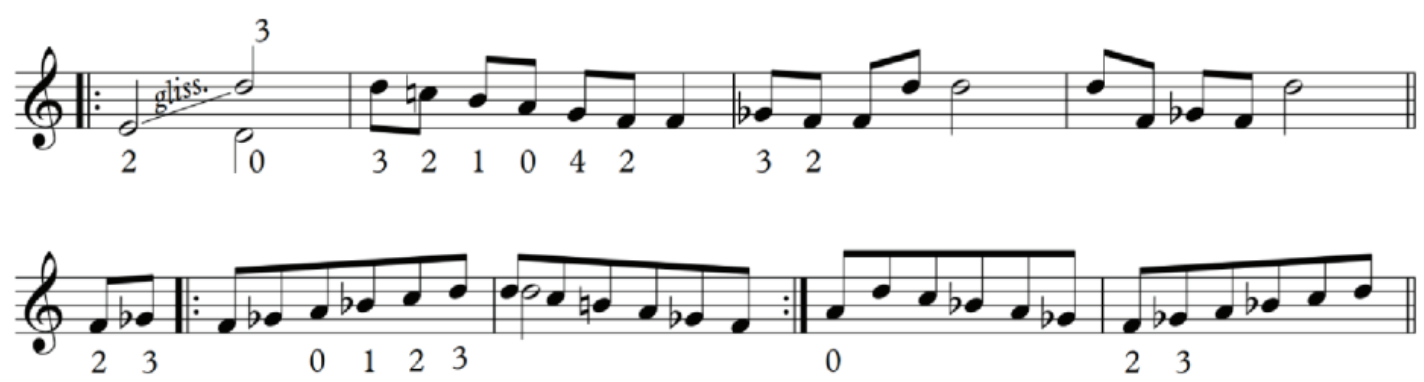

Figure 3-8. Two-steps exercise to practice the shifting from the $F$ to $C$.

Firstly, play the $F$ note in the fourth position using the second finger. Secondly, shift to the $D$ note in the fifth position using the third finger. Control the last note using the open string $D$. The next exercise in to shift from the $F-G b$ to $D$ notes, and conversely. Repeatation of the aforementioned exercise to make the stratagem second mature and, in turn, make the shifting from the $\mathrm{F}$ to $\mathrm{C}$ notes could be done directly.

Solution to the problem at the First Movement, Measure 42 of the Shostakovich Cello sonata opus 40

The following exercise (figure 3-9) might be used to solve the problem of the first movement, measure 42 of the Shostakovich cello sonata opus 40 (see figure 2-17).

Firstly, play the $C-E-F$ notes using the first, second, and third fingers, respectively. This exercise should be done repeatedly and the $C$ note should be controlled using the open string $C$. All notes might be varied as depicted in figure 3-9. To minimize the strain during this exercise should be stopped when the cellists feel pain in any part of the body. 


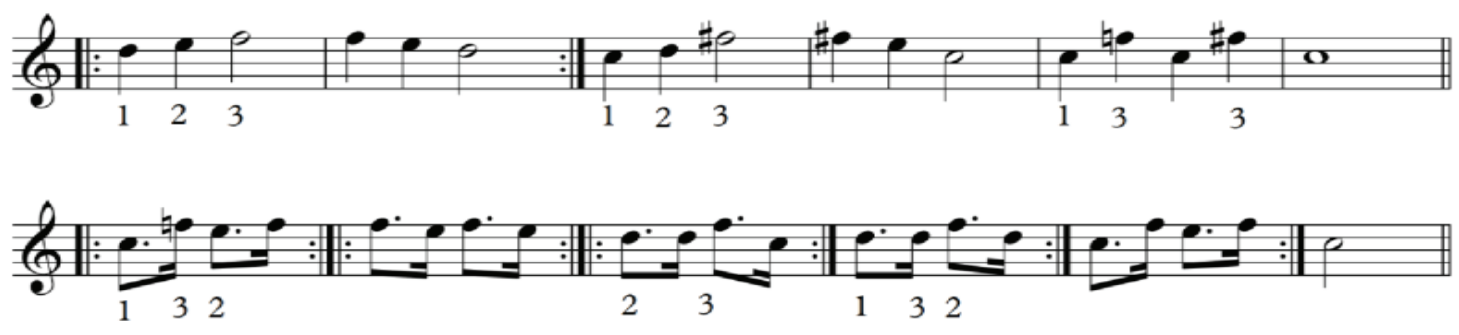

Figure 3-9. The exercise to practice the $C-E-F$ shiftings.

\section{CONCLUSION}

The fingering problems may poses special difficulties to any cellists. According to the author's assessment, there are two problems that warrant special attentions of the cellist. They are the octave and far intervals. The octave intervals may cause serious problems on the performance of short-fingers cellists. The problem occur mainly from the limitation of the spreadability of the short-finger cellists. Nevertheless, the author believes that the inherent short finger are not dead-end. The proposes simple stratagems explored in details in this thesis show that there are many ways to compensate such limitation. More importantly, the author believes that there are still many stratagems to be explored. The far intervals, that become serious problem for any cellists, may also be mastered through some simple stratagems. As we can see many far intervals that may previously be seen difficult problems may not be difficult in their self. The problem may actually come from our limitation to find many side track. Such side-tracks, that may not follow the traditional principles or rules of fingering, should not be regarded as a kind of desertion. They should be regards as products of creative minds, instead. The results show that, what is shown that every cellist are anatomically different. The fingers of the cellists are naturally very flexible. It cannot be converted to another cellists. So flexibly that it is possible to overcome the problem in a simple and convenient.

\section{BIBLIOGRAPHY}

Clarke, Eric. 2010 Music and Mind in Everyday Life. Oxford University Press. Cograss, Ulla. 2001. For The Love of Music. Mcmillan Ltd, New York.

Eisenberg, Maurice 1957.Cello Playing Today. London. Lavender Publication LTD. 147 G, Verlag Henle. 1977. Brahms Sonata Klavier und Violoncello No.1 op, 38 Munchen. Leonard Rose. 2000 Shostakovich Cello Sonata International Music Company no. 2087 New York.

Stowell, Robin. 1999. Enjoyment of The Cello. United Kingdom. Cambride University Press.

Stowell, Robin. 2000 String Quartet. Sage, London.

Pleasant, Hendry. 1990. Music Criticsms, Sage, London.

Welden, V. 1999. The Cambride Companion to the Cello. Cambride University Press.269.

Zen-On. 2000. Shostakovich Sonata Cello and Piano opus 40, Tokyo. 